\title{
ACTIVITY-DEPENDENT SHRINKAGE OF EXTRACELLULAR SPACE IN RAT OPTIC NERVE: A DEVELOPMENTAL STUDY ${ }^{1}$
}

\author{
B. R. RANSOM, ${ }^{2}$ C. L. YAMATE, AND B. W. CONNORS \\ Department of Neurology, Stanford University School of Medicine, Stanford, California 94305
}

Received June 26, 1984; Accepted August 22, 1984

\begin{abstract}
Activity-dependent shrinkage of extracellular space (ECS) is described in a simple model of the mammalian central nervous system, the rat optic nerve. In response to neural activation, the ECS of the mature nerve rapidly and reversibly decreases by as much as $20 \%$. Activity-dependent ECS shrinkage is not present in neonatal nerves but develops over the first 2 weeks of life, roughly coincident with the appearance of glial cells in this structure. These and other observations suggest that activity-dependent ECS shrinkage results from fluid and electrolyte movements into glial cells.
\end{abstract}

The mammalian central nervous system (CNS) responds to a wide variety of stimuli by swelling (Hochwald and Camins, 1981). The mechanisms which account for cell swclling in this tissue are poorly understood and are not likely to be the same under all circumstances (Hertz, 1981). For example, the rapid and reversible increases in brain cell volume which accompany relatively physiological stimuli, including neural activity (Lipton, 1973; Dietzel et al., 1982), are probably mediated differently from the swelling often seen in association with anoxia, inflammation, or CNS neoplasia (Hochwald and Camins, 1981). Rapid increases in brain cell volume associated with concurrent shrinkage of the extracellular space (ECS) are of particular interest. Such changes may secondarily alter extracellular concentrations of ions and neurotransmitters, extracellular current flow, and tissue oxygenation (by increasing intercapillary distances) (Bourke et al., 1980).

The developing rat optic nerve has proven to be a very useful preparation for the study of activity-dependent changes of extracellular potassium concentration $\left(\left[\mathrm{K}^{+}\right]_{0}\right.$; Connors et al., 1982). At birth, its axons are of relatively uniform diameter and entirely premyelinated (Foster et al., 1982); glial cells are very rare and undifferentiated. Nerve maturation and glial proliferation proceed rapidly during the first 2 to 3 postnatal weeks. Using ion-sensitive microelectrodes, we have analyzed neural activity-dependent ECS shrinkage in rat optic nerves at different ages.

\section{Materials and Methods}

Optic nerves from pigmented Long-Evans rats, 1 to 40 days old, were dissected free, placed in a recording chamber maintained at $37^{\circ} \mathrm{C}$, and continuously bathed in an oxygenated physiological saline containing $5 \mathrm{~mm}\left[\mathrm{~K}^{+}\right]$(Connors et al., 1982). The standard superfusion solution contained (in millimolar concentration): $\mathrm{NaCl}, 124 ; \mathrm{KCl}, 5 ; \mathrm{NaH}_{2} \mathrm{PO}_{4}$,

${ }^{1}$ We thank D. Kunis and J. Kadis for technical assistance and C. Joo for manuscript preparation. This work was supported by National Institutes of Health Grants NS 00473 and NS 15589 (B. R. R.) and NS 19510 (B. W. C.).

${ }^{2}$ To whom all correspondence should be addressed.
$1.25 ; \mathrm{MgSO}_{4}, 2 ; \mathrm{CaCl}_{2}, 2 ; \mathrm{NaHCO}_{3}, 26$; dextrose 10 ; saturated with $95 \%$ $\mathrm{O}_{2}$ and $5 \% \mathrm{CO}_{2}$. Double-barreled $\mathrm{K}^{+}$-sensitive microelectrodes were prepared with Corning 477317-type liquid ion exchange resin and calibrated in a conventional fashion (Walker, 1971; Lux, 1974). The tip of the electrode assembly was positioned toward the center of each nerve and adjusted to give the maximum field potential. A suction electrode stimulated the nerve at an intensity 1.5 times that giving the maximum field potential amplitude (see Fig. 4).

Alterations of ECS volume were measured by adding $10 \mathrm{~mm}$ choline chloride or $5 \mathrm{mM}$ tetramethylammonium bromide (TMA) to the normal bathing medium. An appropriate amount of $\mathrm{NaCl}$ was deleted to balance the tonicity. The ion-sensing microelectrode assembly used here is far more sensitive to choline ${ }^{+}$and $\mathrm{TMA}^{+}$than it is to $\mathrm{K}^{+}$; in the presence of choline ${ }^{+}$or $\mathrm{TMA}^{+}$, under physiologic conditions, voltage fluctuations reflect changes in their concentrations alone (Phillips and Nicholson, 1979; Hansen and Olsen, 1980). When tested in calibration solutions containing $10 \mathrm{mM}$ choline ${ }^{+}$or $5 \mathrm{mM} \mathrm{TMA}^{+}$, the ion-sensitive electrode did not respond to $\left[\mathrm{K}^{+}\right]$changes between 3 and $20 \mathrm{mM}$. Because of their size and charge, $\mathrm{TMA}^{+}$and choline ${ }^{+}$are largely restricted to the ECS (Nicholson and Phillips, 1981), and changes in the volume of this compartment due to transmembrane water shifts alter the concentration of $\mathrm{TMA}^{+}$or choline ${ }^{+}$. Variations in ECS volume are calculated using the following expression (Dietzel et al., 1980):

percentage of shrinkage of ECS

$$
=\left(1-\frac{\left[\mathrm{TMA}^{+}\right]_{0} \text { before activity }}{\left[\mathrm{TMA}^{+}\right]_{0} \text { after activity }}\right) \times 100
$$

\section{Results}

As previously described (Connors et al., 1982), the magnitude of activity-dependent $\left[\mathrm{K}^{+}\right]_{0}$ change depends importantly on age. When stimulated repetitively, 1- to 4-day-old optic nerves exhibited maximum $\left[\mathrm{K}^{+}\right]_{0} \mathrm{~s}$ of 15 to $20 \mathrm{mM}$ (Fig. $1 A$ ). During the second postnatal week, activity-dependent increases in $\left[\mathrm{K}^{+}\right]_{0}$ became limited to no more than 10 to $12 \mathrm{mM}$, the socalled "ceiling level" for extracellular $\mathrm{K}^{+}$accumulation under mature physiological circumstances (Heinemann and Lux, 1977; Connors et al., 1982). When 10-sec trains of stimuli were applied to adult nerves in the presence of choline ${ }^{+}$or $\mathrm{TMA}^{+}$, the measured concentrations of these ions increased, indicating a shrinkage of the ECS. This activity-dependent ECS shrinkage was reversible and had a slower time course than corresponding 
A.

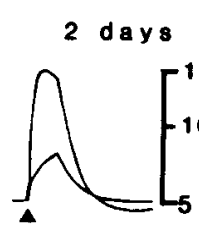

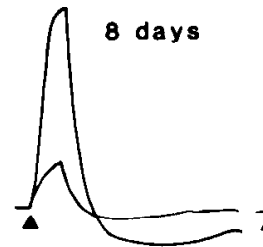

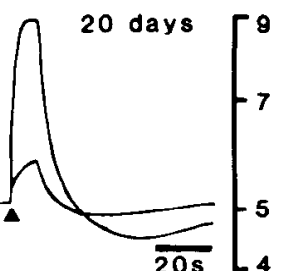

$\underset{\text { E }}{\stackrel{\Sigma}{E}}$
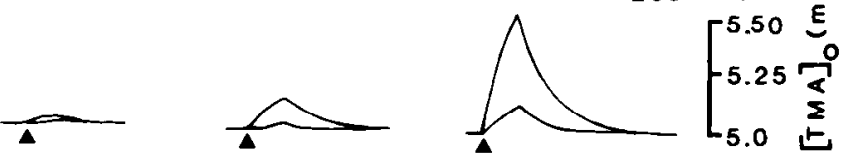

B.

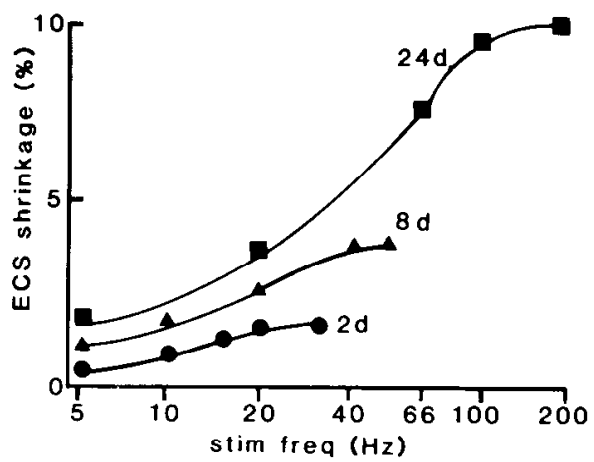

Figure 1. A, Age dependency of evoked increases in $\left[\mathrm{K}^{+}\right]_{0}$ (normal Ringer's solution; top traces) or [TMA $\left.{ }^{+}\right]_{0}(5 \mathrm{mM}$ TMA added to Ringer's solution; bottom traces). Responses to $10-\mathrm{sec}$ trains at two frequencies are shown for nerves at three different ages; 2 days $(5$ and $20 \mathrm{~Hz}), 8$ days $(5$ and $40 \mathrm{~Hz})$, and 20 days $(10$ and $100 \mathrm{~Hz})$. Maximal evoked $\left[\mathrm{TMA}^{+}\right]_{0} \mathrm{~s}$ progressively increased with age. Note the separate $\left[\mathrm{K}^{+}\right]_{0}$ scale for 2-day-old nerve. $B$, Graph showing maximum ECS shrinkage (percentage) as a function of stimulus frequency (10-sec trains) for nerves of three different ages. The maximum frequency which optic nerves can follow increases with age.

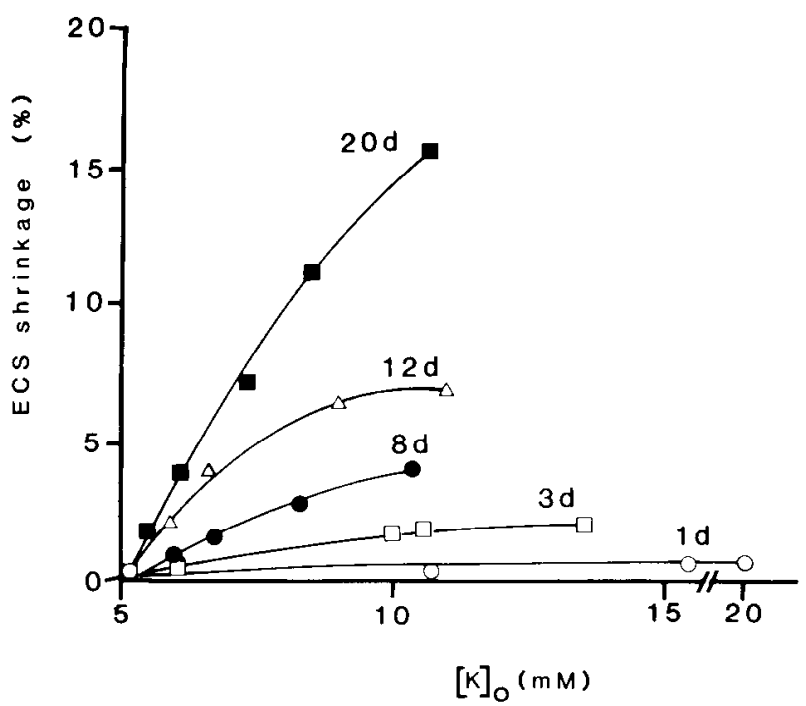

Figure 2. Graph of maximum ECS shrinkage as a function of maximum $\left[\mathrm{K}^{+}\right]_{0}$ for nerves of three different ages stimulated at different frequencies. This graph was constructed from data as in Figure $1 \mathrm{~A}$.

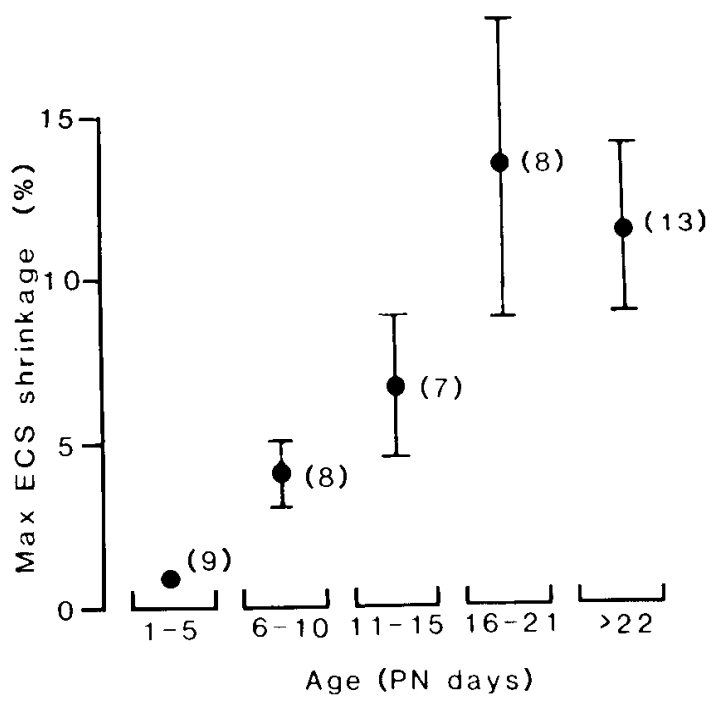

Figure 3. Graph illustrating maximum ECS shrinkage as a function of postnatal $(P N)$ age. Each point is mean $\pm \mathrm{SD}$ (the standard deviation for the youngest groups is less than the width of the point) derived from the number of nerves shown in parentheses. The values shown for the two youngest age groups are each significantly different from those of the two oldest groups $(p<0.001$, Student's $t$ test for matched groups).
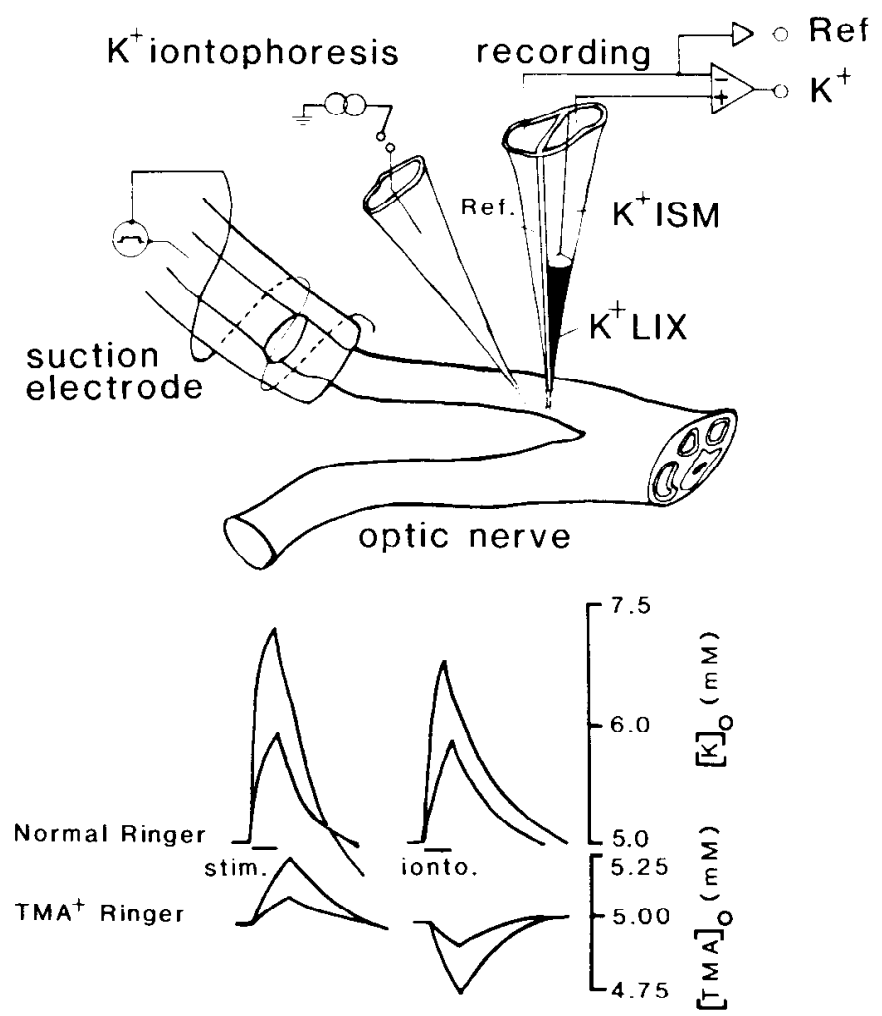

Figure 4. Experimental arrangement for recording iontophoretic increases of $\left[\mathrm{K}^{+}\right]_{0}$. The $\mathrm{K}^{+}$electrode assembly consisted of a reference (Ref.) barrel filled with $0.9 \% \mathrm{NaCl}$ and an ion-selective microelectrode ( $I S M$ ) filled with $\mathrm{K}^{+}$liquid ion exchanger $\left(K^{+} L I X\right.$; Corning no. 477317). The reference barrel records field potentials, and this common mode signal is subtracted from the $\mathrm{K}^{+}$barrel signal to obtain a voltage proportional to $\left[\mathrm{K}^{+}\right]_{0}$. The iontophoretic pipette contained $150 \mathrm{~mm}$ $\mathrm{KCl}$ and was positioned within $100 \mu \mathrm{m}$ of the recording assembly. Below the drawing the effects of stimulated increases in $\left[\mathrm{K}^{+}\right]_{0}$ are compared to those of iontophoretically increased $\left[\mathrm{K}^{+}\right]_{0}$ in terms of ECS shrinkage (see the text). 
A

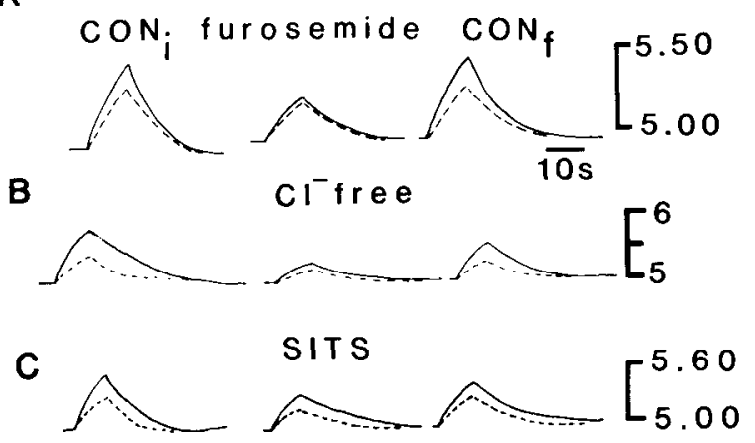

Figure 5. Effects of 15-min exposure to furosemide (10 mM), SITS (1 $\mathrm{mM}$ ), or $\mathrm{Cl}^{-}$-free solution (proprionate or acetate substitution) on stimulated increases in $\left[\mathrm{TMA}^{+}\right]_{0}$. Con ${ }_{i}$, initial control; $\mathrm{Con}_{f}$, final control, obtained $15 \mathrm{~min}$ after switching back to normal solution.

changes in $\left[\mathrm{K}^{+}\right]_{0}$ (Fig. $1 A$ ). In contrast to adult nerves, stimulation of nerves 1 to 4 days old produced little or no change in TMA or choline concentrations (Fig. $1 A$, lower traces).

When activity-dependent ECS shrinkage was seen, its magnitude depended upon the frequency of the stimulus train (Fig. $1 B$ ). There was also a close correlation between the magnitude of the change in evoked $\left[\mathrm{K}^{+}\right]_{0}$ and the amount of the ECS shrinkage (Fig. 2). The steepness of this relationship increased for the first 20 days of life and then became relatively constant.

We determined the developmental timetable for activitydependent ECS shrinkage in 45 optic nerves from animals 1 to 40 days of age. Nerves were first stimulated (10-sec trains) in normal solution to determine the stimulus parameters which produced the maximum $\left[\mathrm{K}^{+}\right]_{0}$ increase. The solution was then switched to one containing $\mathrm{TMA}^{+}$and the same stimulus parameters were reapplied to test for changes in ECS volume. The relationship between maximum ECS shrinkage and postnatal age is shown in Figure 3. Significant ECS shrinkage first appeared in animals approximately 1 week old and increased progressively before reaching a stable level of 10 to $15 \%$ during the third week. The maximal values plotted in Figure 3 specifically refer to results obtained using 10 -sec trains; greater amounts of ECS shrinkage (up to $20 \%$ ) were often seen with more prolonged stimulation in older nerves.

The temporal correspondence between evoked $\left[\mathrm{K}^{+}\right]_{0}$ and ECS shrinkage (Figs. 1 and 2), along with evidence from other models of brain cell swelling (e.g., Kimelberg, 1979), suggested a causal relationship between increases in $\left[\mathrm{K}^{+}\right]_{0}$ and ECS shrinkage. We tested the possibility that increases in $\left[\mathrm{K}^{+}\right]_{0}$ were directly and exclusively responsible for initiating shrinkage of the ECS by iontophoretically applying this ion to the ECS of adult rat optic nerves. An iontophoretic pipette containing $150 \mathrm{mM} \mathrm{KCl}$ was positioned within $100 \mu \mathrm{m}$ of the $\mathrm{K}^{+}$sensitive microelectrode such that iontophoretic currents produced measurable increases in $\left[\mathrm{K}^{+}\right]_{0}$ (Fig. 4). The bathing solution was then switched to one containing $\mathrm{TMA}^{+}$, and the iontophoretic application of $\mathrm{K}^{+}$was repeated. As seen in Figure 4 , iontophoretic application of $\mathrm{K}^{+}$failed to produce ECS shrinkage; in fact, there was a dose-dependent increase in ECS as indicated by the reduction in the $\mathrm{TMA}^{+}$signal. In contrast, a similar increase in $\left[\mathrm{K}^{+}\right]_{0}$ due to neural stimulation was associated with a $\left[\mathrm{TMA}^{+}\right]$increase and, therefore, an ECS shrinkage (Fig. 4). Thus, an increase in $\left[\mathrm{K}^{+}\right]_{0}$ may be a necessary condition for ECS shrinkage, but it is not by itself sufficient.

CNS tissue swelling (Lipton, 1973; Kimelberg, 1979) and cell volume regulation, in general, appear to depend upon anion transport systems (Skoff et al., 1976; Fisher et al., 1981; Hertz, 1981; Russell, 1983). Activity-dependent ECS shrinkage was reduced as much as $70 \%$ by exposure to known blockers of these systems (Heinemann and Lux, 1977): $\mathrm{Cl}^{-}$-free solution (all $\mathrm{Cl}^{-}$substituted with either propionate or acetate), SITS (1 $\mathrm{mM}$; 4-acetamido-4-isothiocyanostilbene-2,2' -disulfonic acid), and furosemide $(10 \mathrm{mM})$. The effects of these treatments gradually reversed after switching back to control solution (Fig. 5). None of these treatments produced significant changes in the maximum $\left[\mathrm{K}^{+}\right]_{0}$ which was evoked by stimulus trains in non$\mathrm{TMA}^{+}$-containing solutions (not illustrated). These results imply that anion transport systems are importantly involved in activity-dependent ECS shrinkage.

\section{Discussion}

Structurally, the major event occurring in the rat optic nerve coincident with the development of activity-dependent ECS shrinkage is the proliferation of glial cells (Fig. 6). The rat optic nerve contains almost no glia at birth, but over the first 2 weeks of life it is populated first with astrocytes and then with oligodendrocytes (Skoff et al., 1976). Axon diameters remain constant during the first week, and the first wraps of myelin do not occur until the second week (Foster et al., 1982) (Fig. 6). The appearance of activity-dependent ECS shrinkage slightly lags the birth of glial cells; this may represent the time necessary for the development of mature glial function corresponding to the period of morphological differentiation which follows final cell division (Skoff et al., 1976). Alternatively, the

Figure 6. Comparison of the time courses of maximal activity-dependent ECS shrinkage, myelination (defined as one complete wrap of compact myelin; from Foster et al., 1982), and glial cell proliferation as judged by the time of final cell division (based on $\left[{ }^{3} \mathrm{H}\right]$ thymidine labeling; from Skoff et al., 1976). Morphological features permitted the labeled cells per section to be recognized as astrocytes (Astro.) or oligodendrocytes (Oligo.).

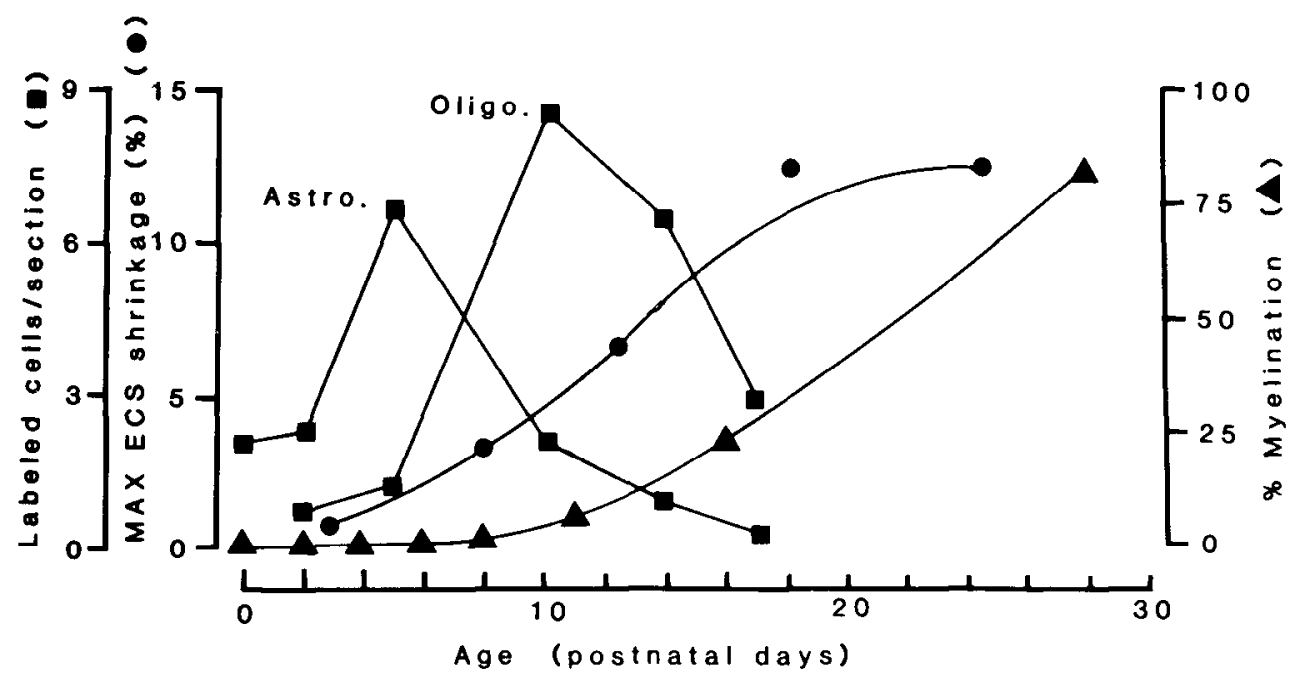


lag may arise from a gradual increase in the percentage of tissue volume occupied by glial cells as they grow.

Previous studies on the mammalian CNS have shown that the absolute dimensions of the ECS decrease during postnatal development (Vernadakis and Woodbury, 1965; Bondareff and Pysh, 1968; Van Harreveld, 1972). A morphometric study on developing rat cortex showed a reduction in ECS of from $40.5 \%$ of tissue volume at 10 days to $26.3 \%$ at 21 days (Bondareff and Pysh, 1968). Conceivably, this could contribute to the developmental changes in activity-dependent ECS shrinkage reported here. If one assumed that at all stages of development neural activity caused a fixed amount of cellular swelling (involving both axons and glial cells) at the expense of extracellular volume, then the magnitude of observed ECS shrinkage would increase as the absolute size of the ECS decreased. If the ECS decreased from $40 \%$ to $20 \%$ with development and neural activity caused a constant $3 \%$ increase in cell volume, the resulting ECS shrinkage would be $4.5 \%$ and $12 \%$, respectively. Thus, even extreme changes in absolute ECS volume are insufficient to solely account for the developmental trend reported here (i.e., Fig. 3). Furthermore, the developmental changes in ECS dimensions may be more complicated than suggested above, with an early phase of ECS increase preceding the steady decrease in ECS (Caley and Maxwell, 1970). The large increase in activity-dependent ECS shrinkage which occurs during this early period (i.e., the first 10 postnatal days; Fig. 3) could not, therefore, be explained by the above mechanism. Finally, available evidence suggests that swelling within the CNS does not involve small, nonmyelinated axons (Van Harreveld, 1972). To summarize, changes in resting ECS dimensions may influence the magnitude of activity-dependent ECS shrinkage, but they cannot account for its striking developmental course.

The temporal coincidence of glial proliferation and activitydependent ECS shrinkage, coupled with the results of studies using anion transport blockers, suggests that dynamic ECS shrinkage results from fluid and electrolyte shifts into glial cells mediated by specific anion transport systems. Similar anion transport processes have been described in neuronal membranes (Russell, 1983), but the absence of ECS shrinkage in essentially glia-free neonatal nerves argues against a quantitatively significant contribution by axons to this process (cf. Van Harreveld, 1972). Brain cell swelling elicited in other experimental models may utilize similar mechanisms (Kimelberg, 1979; Bourke et al., 1980; Hertz, 1981). The activitydependent event(s) which triggers glial swelling may be a metabolic alteration such as a change in acid-base balance or local changes in $\mathrm{CO}_{2}$ or $\mathrm{O}_{2}$ tension (Kraig et al., 1983; cf. Kimelberg, 1979). It is unlikely that increases in $\left[\mathrm{K}^{+}\right]_{0}$ are directly responsible for glial swelling (Fig. 4). Additionally, a spatial buffering mechanism (Deitzel et al., 1980) for $\mathrm{K}^{+}$cannot be the sole explanation for swelling in this situation, since this mechanism should not be influenced by anion transport blockers. These observations provide insight into the mechanisms involved in the ionic and fluid homeostasis of the mammalian CNS and establish the developing rat optic nerve as a useful model system for investigating these questions.

\section{References}

Bondareff, W., and J. Pysh (1968) Distribution of the extracellular space during postnatal maturation of rat cerebral cortex. Anat Rec. 160: $773-780$
Bourke, R. S., H. K. Kimelberg, L. R. Nelson, K. D. Barron, E. Aven, A. J. Popp, and J. B. Waldman (1980) Biology of glial swelling in experimental brain edema. Adv. Neurol. 28: 99-109.

Caley, D. W., and D. S. Maxwell (1970) Development of the blood vessels and extracellular spaces during postnatal maturation of rat cerebral cortex. J. Comp. Neurol. 138: 31-48.

Connors, B. W., B. R. Ransom, D. M. Kunis, and M. J. Gutnick (1982) Activity-dependent $\mathrm{K}^{+}$accumulation in the developing rat optic nerve. Science 216: 1341-1343.

Dietzel, I., U. Heinemann, G. Hofmeier, and H. D. Lux (1980) Transient changes in the size of the extracellular space in the sensorimotor cortex of cats in relation to stimulus-induced changes in potassium concentration. Exp. Brain Res. 40: 432-439.

Dietzel, I., U. Heinemann, G. Hofmeier, and H. D. Lux (1982) Stimulusinduced changes in extracellular $\mathrm{Na}^{+}$and $\mathrm{Cl}^{-}$concentration in relation to changes in the size of the extracellular space. Exp. Brain Res. 46: $73-84$.

Fisher, R. S., B. E. Persson, and K. R. Spring (1981) Epithelial cell volume regulation: Bicarbonate dependence. Science 214: 1357-1358.

Foster, R. E., B. W. Connors, and S. G. Waxman (1982) Rat optic nerve: Electrophysiological, pharmacological and anatomical studies during development. Dev. Brain Res. 3: 371-386.

Hansen, A. J., and C. E. Olsen (1980) Brain extracellular space during spreading depression and ischemia. Acta Physiol. Scand. 108: 355365 .

Heinemann, U., and H. D. Lux (1977) Ceiling of stimulus induced rises in extracellular potassium concentration in the cerebral cortex of cat. Brain Res. 120: 231-249.

Hertz, L. (1981) Features of astrocytic function apparently involved in the response of central nervous tissue to ischemia-hypoxia. J. Cerebral Blood Flow Metab. 1: 143-153.

Hochwald, G. M., and M. B. Camins (1981) Perspectives on experimental and clinical cerebral edema. In Brain Edema, M. de Vlieger, S. A. de Lange, and J. W. Vecks, eds., pp. 19-30, John Wiley \& Sons, Inc., New York.

Kimelberg, H. K. (1979) Glial enzymes and ion transport in brain swelling. In Neural Trauma, A. J. Popp, R. S. Bourke, L. R. Nelson and H. K. Kimelberg, eds., pp. 137-153, Raven Press, New York.

Kraig, R. P., C. R. Ferreira-Filho, and C. Nicholson (1983) Alkaline and acid transients in cerebellar microenvironment. J. Neurophysiol. 49: $831-850$.

Lipton, P. (1973) Effects of membrane depolarization on light scattering by cerebral cortical slices. J. Physiol. (Lond.) 231: 365-383.

Lux, H. D. (1974) Fast recording ion specific microelectrodes: Their use in pharmacological studies in the CNS. Neuropharmacology 13: $509-517$.

Nicholson, C., and J. M. Phillips (1981) Ion diffusion by tortuosity and volume fraction in the extracellular microenvironment of the rat cerebellum. J. Physiol. (Lond.) 321: 225-257.

Phillips, J. M., and C. Nicholson (1979) Anion permeability in spreading depression investigated with ion-sensitive microelectrodes. Brain Res. 173: 567-571.

Russell, J. M. (1983) Cation-coupled chloride influx in squid axon. J. Gen. Physiol. 81: 909-925.

Skoff, R. P., D. L. Price, and A. Stocks (1976) Electron microscopic autoradiographic studies of gliogenesis in rat optic nerve. J. Comp Neurol. 169: 313-323.

Van Harreveld, A. (1972) The extracellular space in the vertebrate central nervous system. In The Structure and Function of Nervous Tissue, G. H. Bourne, ed., pp. 449-511, Academic Press, Inc., New York.

Vernadakis, A., and D. M. Woodbury (1965) Cellular and extracellular spaces in developing rat brain. Arch. Neurol. 12: 284-293.

Walker, J. L. (1971) Ion specific liquid ion exchanger microelectrodes. Anal. Chem. 43: 89A-93A. 